\title{
10
}

\section{Development and Future of Flexible Distance Learning in Denmark}

\author{
Susanne Tellerup and Niels Henrik Helms \\ The Dabish Institute for Educational Training of VocationalTteachers, Noerrehus, Thomas B. \\ Thrigesgade 48 B, DK-5000 Odense, Denmark \\ susanne.tellerup@delud.dk
}

Keywords: distance leaming, didactics, compentencies, lifelong learning

\begin{abstract}
The way we have thought about and worked with education and teaching is changing and therefore new challenges, opportunities and problems are raised. The new focus on distance learning and interpretation of the concept can be explained by various interrelated factors like. We will try to describe the situation and development from different angles. Focusing on the pedagogical, technological and organising perspectives.
\end{abstract}

\section{DISTANCE LEARNING}

Distance Learning (DL) was never a 'big thing' in Denmark. Geographic distance is not a problem in this country as such, therefore DL was often considered a second-rate form of learning for people who were unable to attend 'real' education. But this has changed profoundly within a short span of years. A lot of Danes have attended especially the so-called ECDLcourses as distance learning and now e-learning is on everybody's lips as an important part of the national strategy for learning, especially relating to companies' strategies for learning. The new focus on distance learning and interpretation of the concept can be explained by various interrelated factors.

- The growth of accessibility through the spreading of the Internet

- The potentials in and also confidence in ICT in general 
- The demand for continuous learning related to globalisation and change to a knowledge-society

- The individual interest in lifelong learning.

Distance Learning has developed over the last decade - and today it plays a major role in the Danish educational system. How come? One of the answers we may seek lie in the development of ICT. It has given us new possibilities for delivering and organising learning and for access to education.

On an individual level the development of competencies in the knowledge society means that the each and everybody of us face the challenge of constantly improving our competencies and acquiring new ones. If we are talking about Lifelong Learning, the answer is not traditionally organised education. The way we have thought about and worked with education and teaching is changing and therefore new challenges, opportunities and problems are raised.

\subsection{Moving to flexible and distance learning}

In many countries distance education has a long history. But often it has been seen as a kind of 'emergency teaching' and offered to people who could not participate in what was considered 'proper' education..

The establishment of the Open University, its success and the establishment of corresponding institutions gave notion to another dimension, that education could be open. More people gained access to education, which was much in line with the thinking in the 60s and 70s. Education was seen as a vital resource to create a democratic and equal society. In the $80 \mathrm{~s}$ and especially in the $90 \mathrm{~s}$ the development of competencies was in focus. Now education was seen as an investment made by the individual or the company.

At the same time the enhancement of learning was in focus. The problem of organising learning and learning processes as integrated parts of and combined with the work processes and the production in the companies was prominent. And FDL was put on the agenda instead of the former discussion about Open and Distance Education.

\subsection{Changes in the educational landscape}

According to the American Professor James D. Duderstadt, the educational landscape has changed. It has developed from 'education-just-incase' over 'education-just-in-time' to 'education-just-for-me'.

At the same time the real synchronous learning spaces are replaced by asynchronous network learning, and learning can take place everywhere at 
any time. Therefore it is difficult to find your bearings with the old pedagogical theories and methods. New and innovative thinking is needed within the pedagogical field, because the field extends and changes.

To understand the pedagogical needs we first of all must define FDL. With reference to Keegan, we can point out that Distance Learning is characterised by:

- Teacher and learner are quasi-separated

- The existence of an institution scaffolding the learning processes

- Contrary to private studies

- Use of technological media to connect teacher, learner and the subjects

- Dialogue between the teacher and the learner - contrary to the 'teachyour-self' media.

Furthermore Keegan points out the absence of a learning group. But on this point we do not agree with Keegan, a fact that illustrates the differences and difficulties in the definitions of FDL. Contrary to Keegan we find that the social dimension in the learning process can be vital and important. And this point of view is supported by the improvement of the theories about collaborative learning.

The infinite access to information provided by the internet makes it possible to 'learn about', but not to 'learn to be', as Bruner points out. 'Learning to be' depends upon social interactions and the competent combination of different kinds of teaching and learning processes in 'Learning Communities', which can also be virtual.

In our definition of FDL:

- Teacher and learner are separated in time and space

- Subjects and interaction are mediated by technology

- Collaboration and personal communication are both scaffolding the learning processes and establishing a social practice

- An educational institution delivers (the learning package).

And how does FDL differ from Distance Education? Sometimes it does not! It depends upon the individual learning possibilities. Some concepts for Distance Education are very flexible and give room for a variety of learning styles and collaborative processes.

The vital questions are:

- Does the teacher-learner separation enhance the possibilities for the learner both to learn and to complete the course?

- Does the chosen technology enhance flexibility and collaborative learning?

- Are the learning processes designed in the best possible way in relation to the learner's needs and potentials? 


\subsection{From the learner's point of view}

The conference system can be a key-point in FDL. When you choose a conference system, you should consider the folowing.

- Speed - How quickly can the learner get access, both to begin with and during the course?

- Cost - How much does it cost the learner to use the system?

- Interaction - How and with whom can you interact within this conference system?

- Total experience - How do speed, cost, interaction, goals, skills, subject and use relate?

It is important that the technology is not too advanced and complicated. Otherwise the technology can be the inflexible factor that blocks the essential: the enhancement of learning. Again you must consider:

- The learner's needs, conditions and working tasks

- The wanted and expected learning process.

Some very simple rules are important, when you organise and construct e-learning courses and resources:

- Keep it simple

- Show it

- Enhance transparency

- Consider the learner's point of view - over and over again.

You have to structure virtual learning spaces, which scaffold the perception, the survey and personal task of constructing meaning and knowledge.

\subsection{Pedagogy and teachers' competencies}

The competencies of the teachers are another key to FDL. Working with FDL is a didactic challenge rather than a technological challenge. The teacher must use the new learning spaces and design new teaching and learning strategies corresponding with FDL. This means that the teacher must improve many competencies:

- ICT-competence. To use the technology and give advise about common problems.

- Facilitator-competence. To guide in a way so that the learner feels motivated to go on. To use different kinds of guidance-strategies - based on both written and oral communication.

- Internet-communication-competence. To communicate concretely, clearly and constructively in an attentive way without being without taking over. 
- Structural competence. To create structure. In the traditional school the structure is made up by the timetable, the classrooms, the architecture etc. A structure pointing out very clearly what school is all about. With FDL there also are some the signs - but the teacher plays a major part structuring and connecting things.

- Search and navigation competence. To search and navigate on the Internet and to assess material found on the Internet.

- Organisational competence. To organise and inspire. The teacher has to establish and improve the collaborative learning communities.

- Moderator competence. To moderate different kinds of e-discussions and to let the learners be in charge playing different roles.

- Meta-communication-competence. To be above the situation. The teacher should provoke the learner's thinking and acting.

\subsection{The didactic competencies}

The teacher should be able to understand learners in flexible learning. The learners' needs, interests and also their lives and situations. The distinct problems compared to their classroom counterpart call for different competencies but also emphasise some of the competencies of the traditional teacher. First of all teachers of flexible learning must do much of their work before they know the specific students on the course. The content must be well structured and prepared beforehand, learning objectives clearly stated. It is important to create courses, which are open to being structured in a traditional flow, but also leaves room for a more holistic cyclic process.

\subsection{Resources for learning}

The learning resources should be easily accessible first of all. The materials should be developed considering demands like transparency and easy navigation. - And should also be simple in design and language. The important thing is to avoid that the learner feels confused or even stupid. Among other things that means that:

- The learner should know how and when assignments should be posted

- The learner should be sure which parts give credit in the assignments

- The learner should know where and when things are being discussed

- Which parts are optional

- What kind of learning is to be expected from participating in an activity. 


\subsection{Future dialogue and learning environments}

The first problem most developers and providers of FDL face is very often the lack of activity. The participants don't do anything. But when this has been solved other problems arise. Here the question of qualified netdialogue seems extremely important. The dialogue is the core of collaborative learning in a virtual context. - And a new generation of webliterate learners have competencies in using new ways of communication such as chat. But chat is used to establish social contact, becoming members of communities and probably also to define and try out your own identity. Where as net dialogue is about comprehending, developing analytical understanding and seeing the perspectives. Therefore an important part of the FDL-agenda is to develop a flexible learning environment which accommodates the needs and interests of the individual learner and supports the development of communities of practise. Furthermore is it important to construct these environments in a way so that they leave possibilities for the learner to actively play a part in constructing the environments. Taking into account the differences between learners, the developers need to find the right balance here between structure, involvement and room for creativity.

\subsection{Organisation - formulating a strategy}

The logic, structure and also culture relating to FDL are very different from traditional teaching. The development of FDL as the important activity for an organisation therefore calls for:

- Developing a vision for FDL in the organisation

- Establishing competency-units relating to FDL

- Formulating plans, indicators etc. for the development of FDL.

The vision is important because the different individuals in the organisation should be able to develop understanding of their own role in this change. Very many teachers are against FDL because they feel that it endangers their identity as teachers and they are very often correct in that assumption. This should not be hidden but brought out into the open. Emphasising the changing role of the teacher means that in the future the teacher should be able to handle different roles such as developer, facilitator and mediator. The fact that there will still be a need for more traditional teachers might overcome at least some of the resistance.

Competency-units are a way of describing what is needed. There must be different supporting competencies available to the team and a competency unit needs to have access to the necessary infrastructure, resources and be 
organised and placed in the setup in a way which is beneficial to the development and delivery of FDL.

\subsection{Networking}

As stated above each organisation has to find its identity in this development. But working with FDL means that you work in a national and sometimes global context and furthermore it means that you have to focus on your key-competencies. All in all this calls for different types of models and co-operation. One way is to establish networks where one organisation takes care of the technology and delivery and another deals with the content and learning.

Another form is to establish co-operation between institutions, which share interests and benefits from a closer co-operation when developing FDL-courses We have seen this in the area of higher and academic education and also in further education. The important issues for these co-operations and networks seem to be as follows.

- Understanding and developing the core-competencies of your own organisation and seeing how they can interact in a mutually beneficial way with the competencies of other organisations

- Developing dialogue between the participating organisations.

\section{CONCLUDING REMARKS}

The Danish tradition in education emphasising co-operation and dialogue has an important role to play in the further development of FDL. Small is supposed to be beautiful but in the development and in the delivery of traditional distance education that is not necessarily the case. Developing major distance learning programmes based on a concept of broadcasting calls for big industrial organisations with a high degree of specialisation. But in a modern post-industrial world we also need other forms of FDL that emphasise collaboration, co-operation and dialogue. And in this area the Danish tradition of co-operation and also capacity for change will be important. The central issue will be how to develop the relationship between organisation, learning and technology in order to develop learning which can cope with the challenges of 'Learning just in time' and 'learning just for me'.

On the major conference on Distance Learning in Copenhagen in the spring 2000 the Canadian practitioner and theorist Terry Andersson introduced the concepts of 'Big' and 'Small Distance Learning'. He sees Big Distance Learning as the major programmes developed and delivered by big 
providers for a big market, very often for the whole world. But according to Terry Andersson there is and will be a growing demand for 'Small Distance Learning' where specific needs are in focus. These two forms should probably not be seen as contradictions to each other but rather as supplements. We have tried to describe the development from different angles. Focusing on the pedagogical, technological and organising perspectives.

In a somewhat reduced form we can see a relationship between these different angles as illustrated in the model below (Figure 1)

The nucleus of the model shows the traditional distance learning which aims at distributing and providing access to information for a (large) number of learners. The technology should be designed for smooth delivery, which means that it could be radio, traditional mail or the Internet. This mode demands a high degree of division of labour between developers, experts in the subject matter, delivery and control. The best known example of these organisations is the Open University in UK.

At the next level we focus on skills. It could be language, math or vocational skills. Together they share the need for practise and training, and multimedia is often a good way to do that. Developing quality multimedia is however a very expensive task. Therefore the market is often left to major commercial enterprises focusing more on mainstream accessible edutainment than on quality learning. Networks between colleges and private enterprises and European co-operation can be ways of overcoming this problem.

Collaborative virtual and real learning processes are the most important form of learning in the network society.

The individual learner constructs his or her own learning-portfolio (Learning just for me) but the collaborative processes opens up for developing competencies. Now we are at level three in the model. That kind of learning calls for a more flexible, simple and open technology than for advanced solutions. In this perspective the logic of the model might transform! The nucleus would then be that the individual learner develops his or her competency in learning groups working in collaborative GroupWare. 


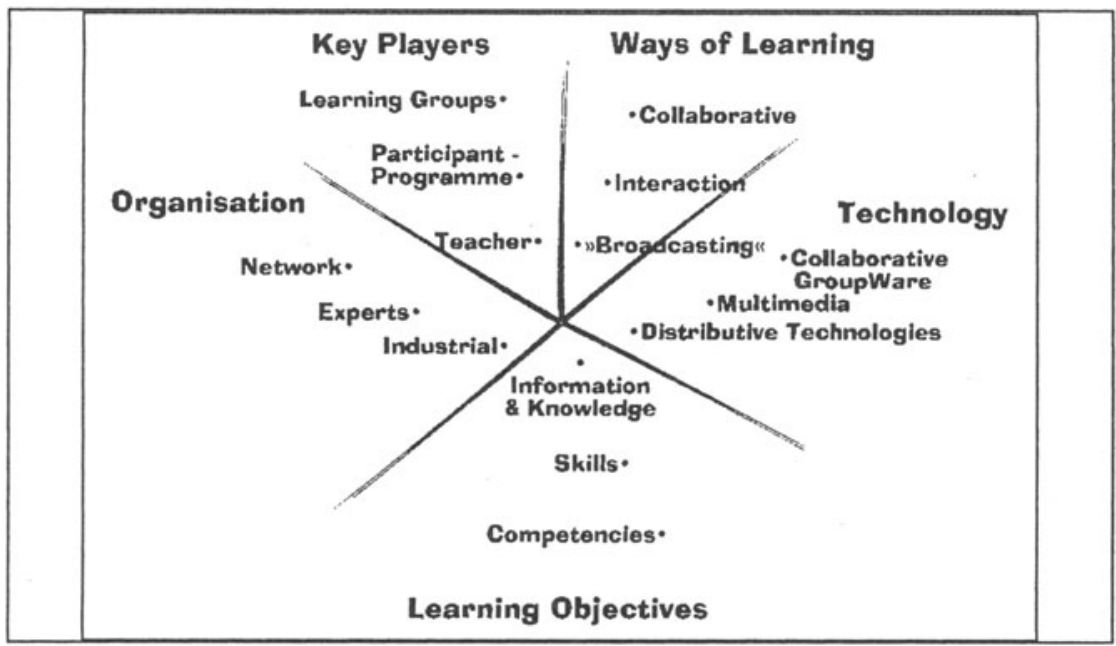

Figure 1. Perspectives of distance learning

And from there identifies the need for training skills or for getting a more formalised education. We are already now in the middle of such a development where individuals create their own learning portfolio related to worklife and personal development and seek the most relevant learning resources on a global market. That means that the learning environment becomes more local (combinations of work and private life) and more global (access to providers of education all over the world).

This is a development where the Danish tradition in general (working in networks on a small scale but with a global market) and also in learning and education (dialogue and co-operation) has much to offer. But if this is to happen the institutions should be focusing on developing virtual dialogue, flexible learning together with the learners and especially combining the potentials of big - and small - distance learning.

\section{REFERENCES}

Andersson, T. (1998) Networked Learning. McGrawHill, Montreal.

Helms, H. Jørgensen, J. J. and Tellerup, S. (1999) Fjernundervisning. Erhvervsskolernes

Forlag Odense, Denmark.

Jarvis, P., Holford, J. and Griffin, C. (1998) Theory and Practice of Learning. Kogan Page, London.

Katz, R. N. (1999) Dancing with the Devil. Jossey Bass, San Francisco.

Keegan, D. (1993) Distance Education: New Perspectives. Routledge, London.

Paloff, R. M. (1999) Building Learning Communities in Cyberspace. Jossey Bass, San Francisco.

Peters, O. (1998) Learning and Teaching in Distance Education. Kogan Page, London. 